\title{
China targets top talent from overseas
}

China has announced a nationwide plan that promises top salaries and attractive funding to elite researchers who are working overseas and willing to return to the country. The plan, known as the one-thousand-talents scheme, aims to boost China's innovation capability. But critics say that its success will depend on whether domestic talent gets similar support, and whether the country's science infrastructure can be reformed.

"The scheme sends a strong signal that the Chinese government values talented people from overseas and welcomes their contribution in key areas of research development," says Zhanqing Li, an atmospheric scientist at the University of Maryland in College Park.

The plan, announced this month by the country's top personnel administration, targets people with full professorships or the equivalent in developed countries. It offers a relocation package of 1 million renminbi (US\$146,000) per person, with salaries and research funding left to universities and institutes to sort out.

Previous approaches - such as the Chinese Academy of Sciences' onehundred-talents scheme and the edu-

STAYING IN THE UNITED STATES

Chinese students who receive their doctoral degrees in the United States are more likely than students from any other country to stay there. China is implementing a new scheme to try to lure the most promising ones back home.

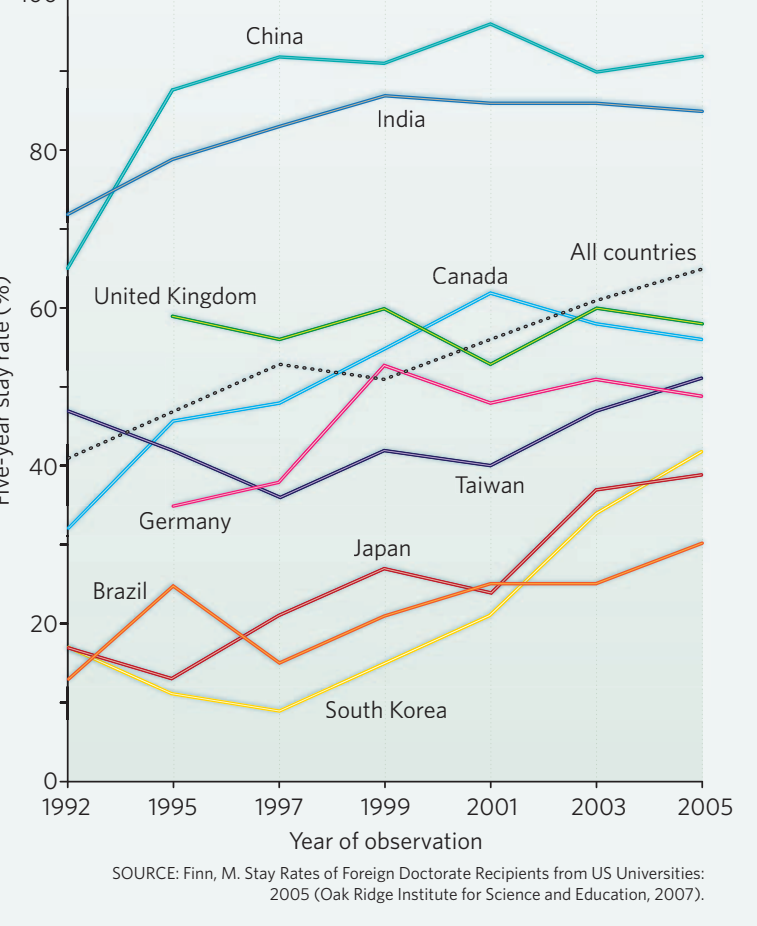

basis." The widely differing criteria for professorship between universities and countries should also be a factor.

Jia says that institutes and universities should develop long-term strategic plans before starting to recruit. In the past, some organizations were more preoccupied with meeting targets than ensuring that the skills and research areas of the recruits were appropriate. "This has led to talented people moving to another organization or even leaving the country," says Jia, who returned to the United States last year after nearly a decade in China.

\section{Domestic discontent}

The generous package of the new talent scheme, especially the salaries, is likely to cause resentment in researchers already in China. Last year, the 1.7-million-renminbi salary of Shi Yigong, whom the Beijingbased Tsinghua University recruited from Princeton University in New Jersey, was leaked and caused an outcry among principal investigators in China, who have an average annual salary of 150,000 renminbi.

Top-range salaries and funding are necessary for attracting the overseas elite, but the resentment of their cation ministry's Yangtze River Scholar Scheme - have lured more than 4,000 researchers, mostly at postdoctoral or assistant-professor levels, back to the country in the past fifteen years.

\section{Time for change}

The new scheme "wouldn't have worked just a few years ago", says Muming Poo, a neuroscientist at the University of California, Berkeley, and director of the academy's Institute of Neuroscience in Shanghai. But given pressures on funding in the developed world, China can offer researchers comparable, if not better, support.

Researchers of non-Chinese

\section{"Without a long-} term commitment to creating such an environment, any talent schemes would be futile." will be eligible for positions as principal investigators on major national projects.

Details have not yet been released on how much the science and education ministries will contribute. But Poo says that the Chinese Academy of Sciences, a ministry-level organization, alone will provide up to 20 million renminbi for top-level scientists as a one-off, start-up package over five years, including annual salaries of up to 1 million renminbi. The number of recruits over the next five years will depend on the balance of demand and supply, and is likely to be in the hundreds.

"The details of how the scheme will be operated will be important," says Rao Yi, dean of the life-sciences school at Peking origins will also be considered, says a source University. Rao warns that the selection process in the personnel and education bureau at the Chinese Academy of Sciences' headquarters in Beijing, who did not want to be identified without official permission to speak. In contrast to the current regulations, the new scheme means that non-Chinese nationals
University. Rao warns that the selection process
should focus on a candidate's potential as well as his or her past academic record. "Some assistant or associate professors may have more potential than full professors," says Wei Jia, a biochemist at the University of North Carolina in Greensboro. "This should be dealt with on an individual domestic peers should not be ignored, say critics. "It is important that researchers recruited to China at a junior stage should be able to compete for the same level of support," says Rao. "There should be a matching talent scheme for domestic scientists."

Still, some doubt whether overseas professors will jump to the call. "Money is important for practical issues," says Li. "But the determinant factor is whether we would be able to be as productive in China as we are in the United States." Some elite researchers may be put off by the scientific culture and policies in China, which historically has neither encouraged critical thinking and intellectual exchange nor ensured fair competition.

"We have a proverb in China: it takes a decade to grow a strong tree and a century to create a nourishing environment in which talents could flourish," says Jia. "Without a long-term commitment to creating such an environment, any talent schemes would be futile." Poo agrees: "Talent schemes and science-infrastructure reform must go hand in hand."

Jane Qiu 


\section{Correction}

In the article 'China targets top talent from overseas' (Nature 457, 522; 2009), we cited an

incorrect salary for Shi Yigong of Tsinghua

University, Beijing. This figure has been removed

from the html version of the story and should

be disregarded in all other versions. Nature

apologizes for the mistake, and for any distress

caused. 